\title{
Artelogie
}

artelogie Recherche sur les arts, le patrimoine et la littérature de I'Amérique latine

$11 \mid 2017$

Délocalités, translocalités et activisme dans l'art électronique et biomédiale latino-américain

\section{La joya contemporánea : artefacto no convencional}

Andrea Piñeros

\section{OpenEdition}

Journals

Edición electrónica

URL: http://journals.openedition.org/artelogie/1702

DOI: 10.4000/artelogie. 1702

ISSN: 2115-6395

Editor

Association ESCAL

Referencia electrónica

Andrea Piñeros, «La joya contemporánea : artefacto no convencional », Artelogie [En línea], 11 | 2017,

Publicado el 15 enero 2018, consultado el 30 abril 2019. URL : http://journals.openedition.org/

artelogie/1702 ; DOI : 10.4000/artelogie.1702

Este documento fue generado automáticamente el 30 abril 2019.

Association ESCAL 


\title{
La joya contemporánea : artefacto no convencional
}

\author{
Andrea Piñeros
}

1 Objeto ornamental en primera instancia, la joya se ampara de los valores intrínsecos de cada cultura, para demostrar poder, riqueza o pertenencia a algún grupo.

Desposeída de un carácter utilitario, a la joya se le imprime un valor diferente que a los otros objetos que nos rodean. Cargada de símbolos, juega un papel exclusivo en el mundo artefactual del hombre que desde sus orígenes, les atribuye poderes mágicos, sociales o personales.

3 En el estudio de la relación hombre-objeto, en este caso hombre- joya, es muy importante remarcar la importancia que juega el entorno. Discreta o llamativa, la joya se muestra y se exhibe, llevando consigo un mensaje que puede ser leído de diferentes maneras, según la cultura y los valores de esta misma.

4 Entre el objeto observado y el que lo observa se crea un dialogo tácito, que permite a los individuos de identificarse y así aunque la joya no tenga una valor utilitario en si misma, juega un papel social de comunicación.

5 Muchas tentativas de definición existen, para tratar de explicar lo que es la joyería contemporánea. Cuando el diccionario define la joya como "un objeto pequeño de gran valor que sirve para adorno" (Diccionario Larousse), la joyería contemporánea viene a interrogar la definición de valor, explorando las nociones de preciosidad y reformulando los códigos de la joyería tradicional.

6 Aunque la palabra joyería esté presente en su nombre, la palabra contemporánea describe mejor la realidad de su practica. Como en el arte contemporáneo, lo que caracteriza esta joyería de vanguardia, es el cuestionamiento de la parte del creador. La relación con el cuerpo, la exploración de materiales y la creación de materias, son nociones que prevalecen, muy lejos de la dimensión decorativa. 


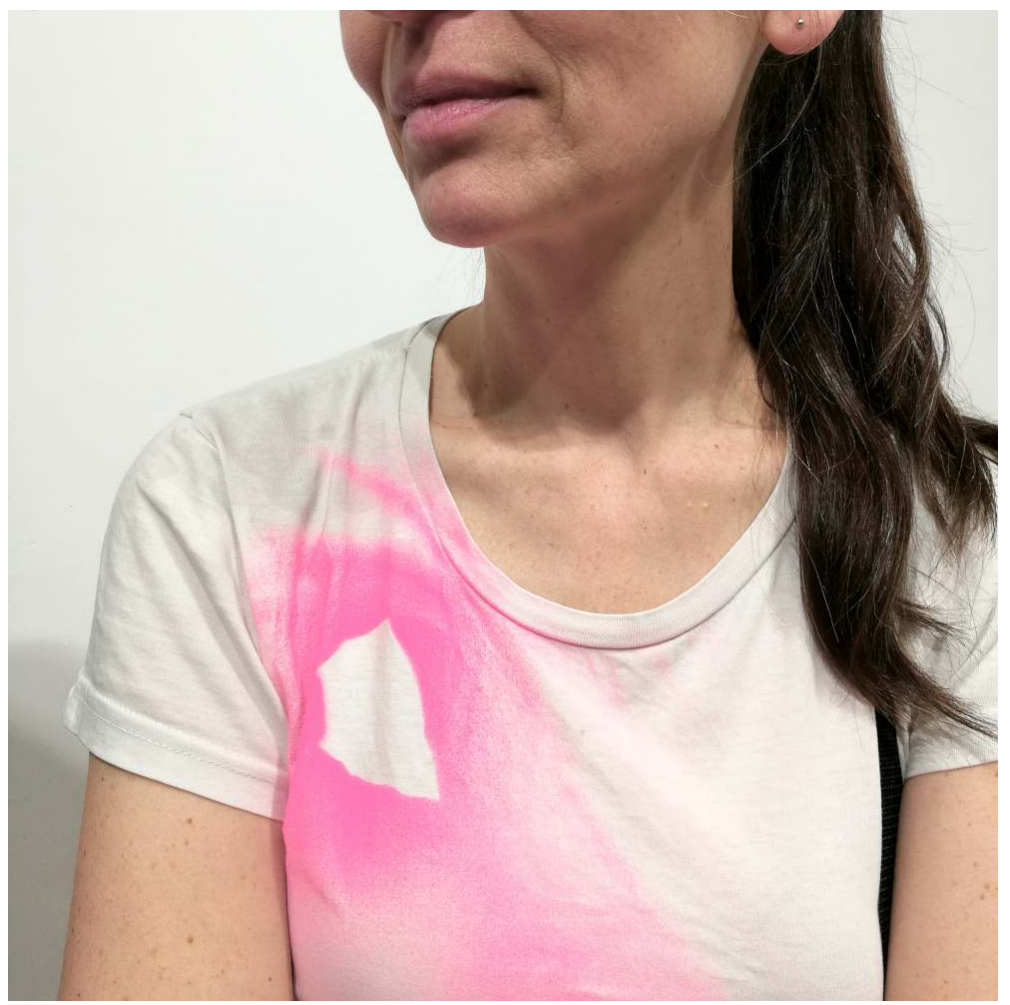

Foto () Andrea Piñeros

La paleta de posibilidades es infinita y de la misma manera que en el dominio escultórico, cada artista se manifiesta de manera individual con resultados tan diversos que hasta a veces puede preguntarse si la obra realmente es una joya.

Durante la exposición de joyería contemporánea "Pink Panthers" (París, 2017), la artista brasilera Stella Bierrenbach, cuyo trabajo suele ser mas cercano a la instalación que a el objeto, decía que finalmente ella se daba cuenta que no había hecho ninguna joya, à parte de aquella que ella llevaba puesta ese día. Se trataba de una camiseta blanca pintada parcialmente con una pintura spray rosada en una zona donde antes había protegido una parte con una silueta en forma de piedra con facetas.

Muchos artistas de joyería contemporánea están profundamente animados por el cuestionamiento sobre la preciosidad, sobre el adorno, y sobre la relación con el soporte de esta joya. Una joya en el muro, sigue siendo una joya o se vuelve escultura? La joyería contemporánea quiere sacar a la joya de su empaque de terciopelo. Entonces se invitan los materiales llamados "pobres", las técnicas se diversifican y se ven influenciadas por la tecnología. El tiempo de trabajo entra dentro de la valorización de la obra y la búsqueda personal se convierte en un espejo de dialogo social.

11 Muy fácil llamarse joya cuando se es de oro o de piedras preciosas, pero en este caso, la tradición esta fuera de juego. Esto lo expresa muy bien la artista Alemana Katja Köditz en su exposición 36h expuesta en París durante el festival de joyería contemporánea, Parcours Bijoux.

12 La pieza es una camisola de locos, completamente bordada con la técnica tradicional de tapicería Gobelinos desarrollada en Francia para decorar los interiores royales. La 
camisola esta desgarrada indicando así que se ha logrado escapar a las tradiciones. (ver foto).

Anecdótica e irreverente, la joya contemporánea es un artefacto no convencional que cumple un papel de comunicación y hace demarcar aquellos que la llevan puesta por su osadía y su capacidad a ejercer su libre albedrío.

14 Esta practica, cuyos limites son porosos continua a desarrollarse, entre las fronteras del arte, del diseño y de la artesanía.

Instalación Katia Köditz

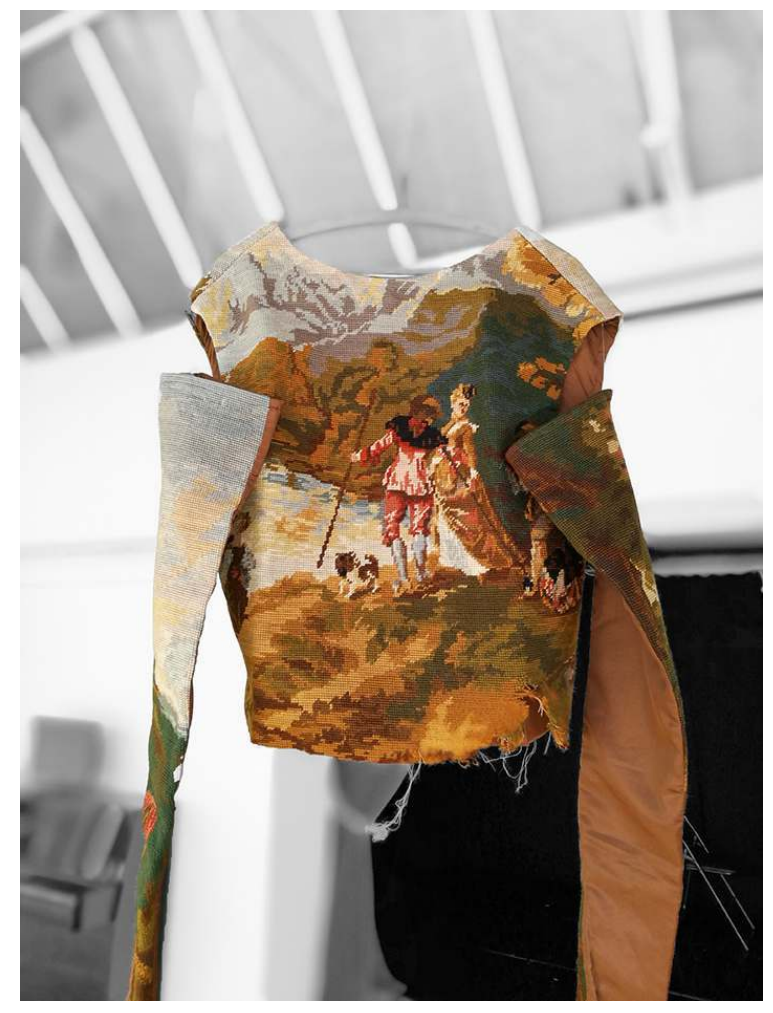

Foto $\subset$ Andrea Piñeros

\section{El “Parcours Bijoux” catalizador de nuevos caminos}

Durante dos meses el Parcours Bijoux, manifestación de joyería contemporánea, se instala en París para hacer de ella la vitrina de esta práctica, con mas de cincuenta proyectos, exposiciones, conferencias y performances, organizadas por artistas y curadores de diferentes países del mundo.

Frente a un vacío institucional en Francia, y sin ninguna ayuda para la promoción de la joyería contemporánea, la asociación "D’un bijou à l'autre" se creó en el año 2011 con el ánimo de federar iniciativas propias. La estrategia fue incentivar a los diferentes actores de la joyería contemporánea, artistas, historiadores, curadores a organizar un evento en el mismo lapso de tiempo y así unir esfuerzos en materia de comunicación.

Para esta segunda edición 2017, la asociación "D’un bijou à l'autre" organizadora del evento, se alía al Museo de Arte Moderno de la cuidad de París, con su exposición Medusa : joyas y tabús. 

encuentra disimulada entre el mundo del lujo y el de la moda. Sin pertenecer ni al uno ni al otro, la joyería contemporánea, no es reconocida plenamente como medio de expresión artística. de curadores de arte contemporáneo, de expertos en joyería y de miembros de asociación D'un bijou à l'autre.

En 2015, 60 proyectos de 120 postulantes fueron seleccionados por un jurado compuesto

Los criterios fueron basados sobre la calidad del trabajo de los artistas y de la temática del proyecto. Todo trabajo con un enfoque puramente comercial fue eliminado.

21 Países como Canadá, Portugal, Italia, Bélgica, Holanda, Colombia, Taiwán y Dinamarca, participaron con una muestra propia de sus artistas.

22 En la otras manifestaciones la participación internacional fue numerosa, desde Australia, pasando por Argentina, Brasil, Chile, hasta Corea y Japón. Mas de trecientos artistas franceses y extranjeros hicieron de este evento una muestra internacional del panorama de la joyería contemporánea.

23 Aun si la joyería contemporánea es una practica marginal, tiene auge en muchos países del mundo. Gracias a las redes sociales, à plataformas como Klimt $02^{1} \mathrm{y}$ a eventos mayores, como, entre otros el Parcours Bijoux, se ha podido crear muchos lazos mas allá de las fronteras y poco a poco crear una comunidad.

24 Aunque las influencias culturales puedan orientar las cualidades estéticas y formales de este tipo de joyería, la idea, la intención única del artista serán siempre su denominador común.

Catalogo du Parcours Bijoux 2017

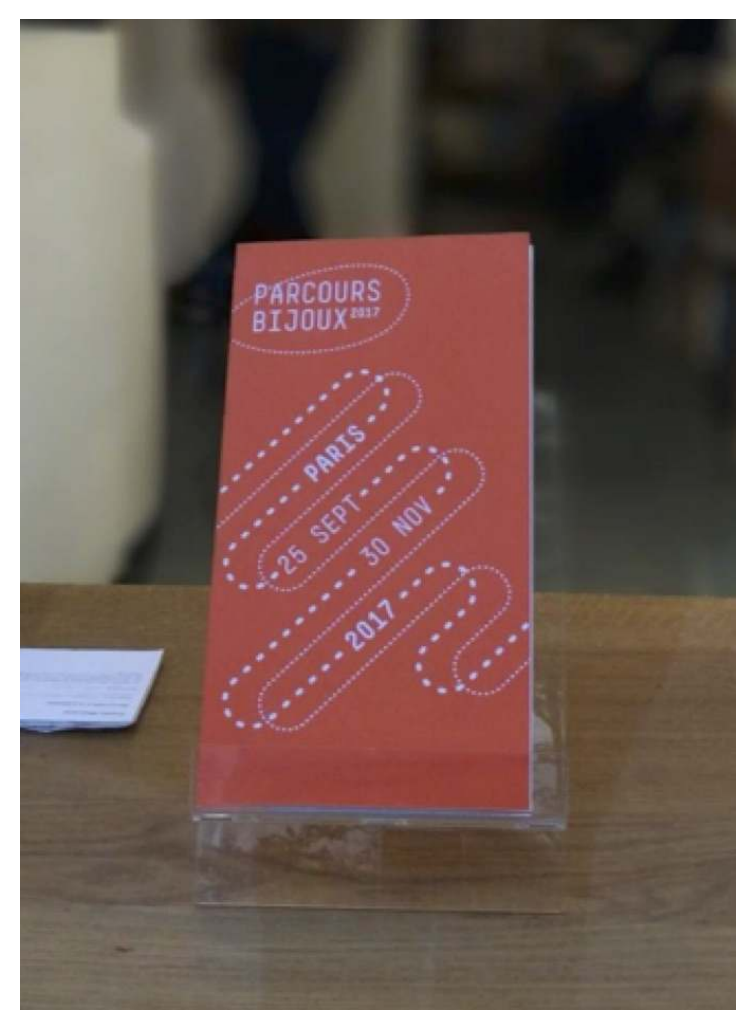

Foto (c) Andrea Piñeros 


\section{Exposición "Ailleurs"}

Qué significa para cada uno estar lejos del sitio se nació, cómo el hecho de vivir en otro
lado actúa en sus vidas, o porqué soñar estar en otro lado para escapar a una realidad, son
puntos de vistas que fueron abordados en esta exposición de joyería contemporánea que
hizo parte del Parcours Bijoux.
La apropiación de este tema, inherente a la evolución del hombre, muestra algunas

Dentro de esta perspectiva internacional, el proyecto AILLEURS, cuya traducción del francés es: en otro lado, se construye con la participación de cinco artistas de orígenes diferentes, en su mayoría latinoamericanos, establecidos en Francia. facetas de la riqueza de la búsqueda artística. El desarrollo conceptual, técnico y estético de la obra de cada una de las artistas es una pequeña muestra de los amplios limites de expresión en el campo de la joyería contemporánea.

Instalación de Andrea Piñeros utilizada en la vitrina de la exposición “Ailleurs"

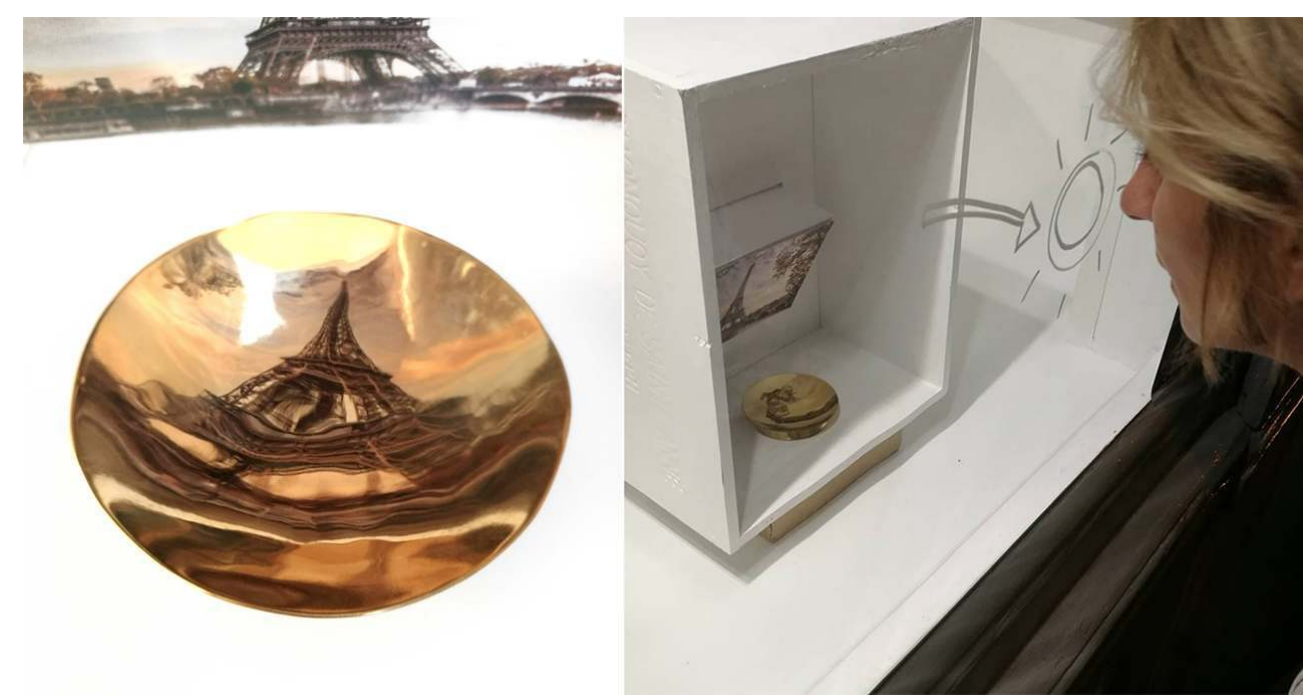

Foto @ Andrea Piñeros

\section{Stella Bierrenbach ( Brasil)}

Stella Bierrenbach no es Alemana como podría imaginarse, cuando se tiene ese apellido. Tampoco es morena ni tiene el cabello rizado como podría esperarse de alguien que viene de Brazil. La imagen que ella envía no corresponde a los estereotipos que los otros tienen de su país y suele sentir una cierta desilusión en los ojos de los otros, cuando tiene que explicarse. "Yo decepciono" se dice Stella, cada vez que conoce a alguien.

Lejos de su país desde hace mucho tiempo, ella se cuestiona sobre la imagen que ella envía o mas bien sobre la imagen que la gente se puede hacer de ella y como eso influye en la construcción de su identidad.

Confrontada a los estereotipos y los clichés, ella toma este punto de partida para su búsqueda artística. 
"Yo no quiero acusar a nadie, pues finalmente todos vivimos rodeados de estereotipos, pero quiero poder reír de esto" dice Stella. "Me gustaría corresponder a esos clichés, para aferrarme a una identidad".

Estudiando la definición de esta palabra Stella encuentra materia para ilustrar sus ideas.

Si al origen "estereotipo" hace referencia à la impresión de un molde construido en plomo para reproducir una imagen, con el tiempo su aplicación metafórica se usa para definir un conjunto de creencias fijas que un grupo tiene respecto a otro.

\section{Collar "Stéreotypes" de Stella Bierrenbach}

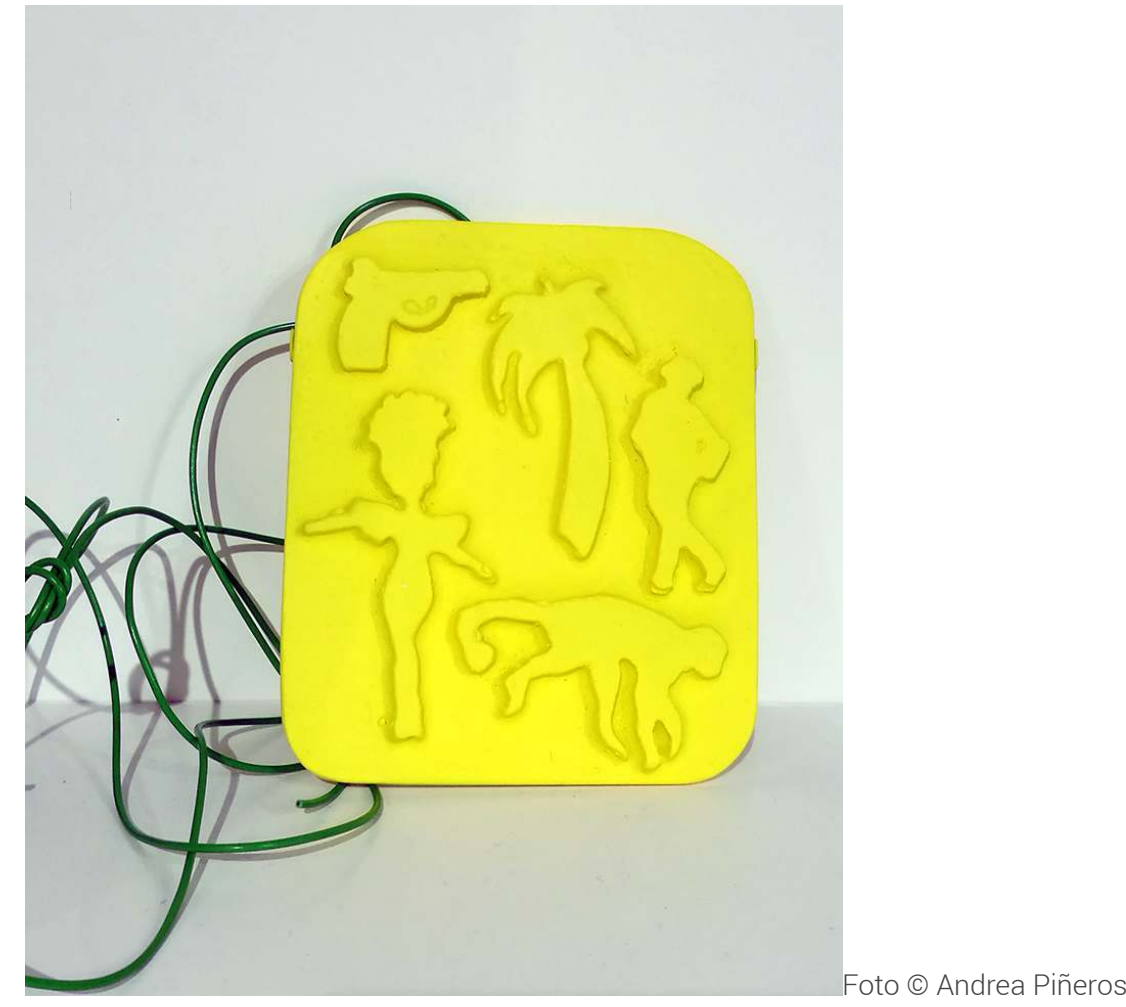
para reproducir formas, porque ella siente así poder guardar la huella de una futura desaparición. Reproducir una pieza a partir de un molde permite de darle forma instantánea à algo que puede ya no estar.

Para su tema sobre los estereotipos, ella propone tres colgantes salidos del mismo molde y el molde mismo haciendo parte de la escena. El molde en tanto que objeto tiene mas valor que sus copias, por ser la matriz capaz de recrear.

El molde puesto sobre un sócalo, indica que es el objeto inmóvil, mientras que las copias están destinadas a alejarse puestas sobre alguien. De manera sutil, Stella nos hace cuestionar sobre el valor de los objetos, y hace un homenaje a las matrices que permiten de recrear la forma. 


\section{Miyuki Kushimizu ( Japon)}

Estando en Francia, Miyuki se vuelve mama y decide no enviar sus hijos a la guardería para poder ejercer su maternidad según su cultura y así poder transmitir lengua y costumbres de una manera mas directa. Al tomar esta decisión nunca se imagino que su mundo iba a cambiar, momento que ella describe como estando dentro de una burbuja.

Esta reflexión será el punto de partida para trabajar el tema "Ailleurs". Ella se dice entonces que estar en otro lado no es solo una cuestión de territorios físicos pero también de territorios mentales.

"No importa el lugar donde se vive, la vida con niños es vivir en otro lado" dice Miyuki. Si estuviera en Japón, seguro estaría encerrada en la misma situación.

Desde su burbuja, ella decide de contarnos su historia de mama, por medio de su obra y su deseo de estar en otro lado. Para esto de basa en dos momentos difíciles de esa realidad : el momento de cambiar los pañales y el de la lactancia.

La primera idea se concretiza con una pieza realizada utilizando el sistema de velcro que sirve para cerrar los pañales, que ella colecciona día a día y los junta creando una materia, que por la acumulación se aleja del aspecto inicial de velcro de pañal. La noción de cantidad, de gestos repetidos la lleva a reflexionar sobre lo repetitivo que es lo cotidiano cuando se tiene hijos pequeños. Su pieza, como una forma de trofeo a su valentía, la va a llamar "Bravo maman".

Collar “Bravo maman” de Miyuki Koshimizu

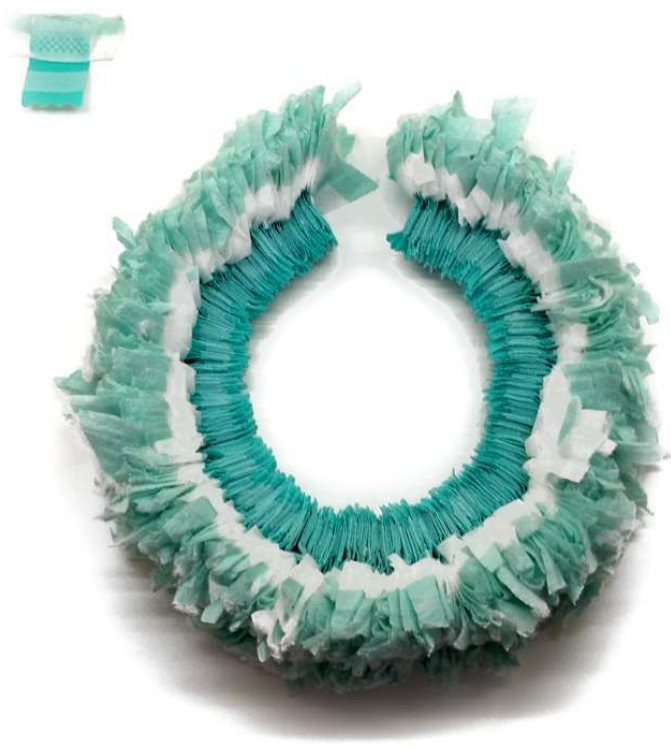

FOTO @ ANDREA PIÑEROS 
La segunda pista tiene que ver con el momento de la lactancia. Al servicio de las necesidades de su hijo, Miyuki se encuentra prisionera de la dependencia a alimentarlo y tiene el sentimiento de ser un objeto. Un anillo con forma de chupo, que obtuvo moldeando su pezón, es la manera de ilustrar este propósito. Fabricado en resina transparente, ella quiere evocar la idea de ausencia y de aislamiento que representa su acto frente a la sociedad.

Anillo "maman tétine" de Miyuki Kushimizu

\section{Andrea Vaggione (Argentina)}

Andrea Vaggione nos quiere hablar de envuelo, de alas, de viaje. Dejar el nido para poder crecer e ir hacia delante rompiendo fronteras en un viaje sin retorno. Con una nota de nostalgia, Andrea mira para atrás y toma consciencia de la distancia y de las nuevas raíces que ha construido en otros territorios.

La consciencia de los lazos que la atan a sus orígenes se refuerzan cuando vuelve y constata que todo sigue intacto y fuerte como antes a pesar del tiempo y de la distancia. Con sus piezas inspiradas de las alas de insectos migratorios, ella quiere ilustrar esta búsqueda del "Ailleurs" de nuevos horizontes.

Las alas están ligadas entre ellas para mostrar la fuerza de las relaciones y el poder de la familia. Atadas por cadenas que aunque permiten movimiento estarán siempre presentes para recordarnos de donde venimos. 


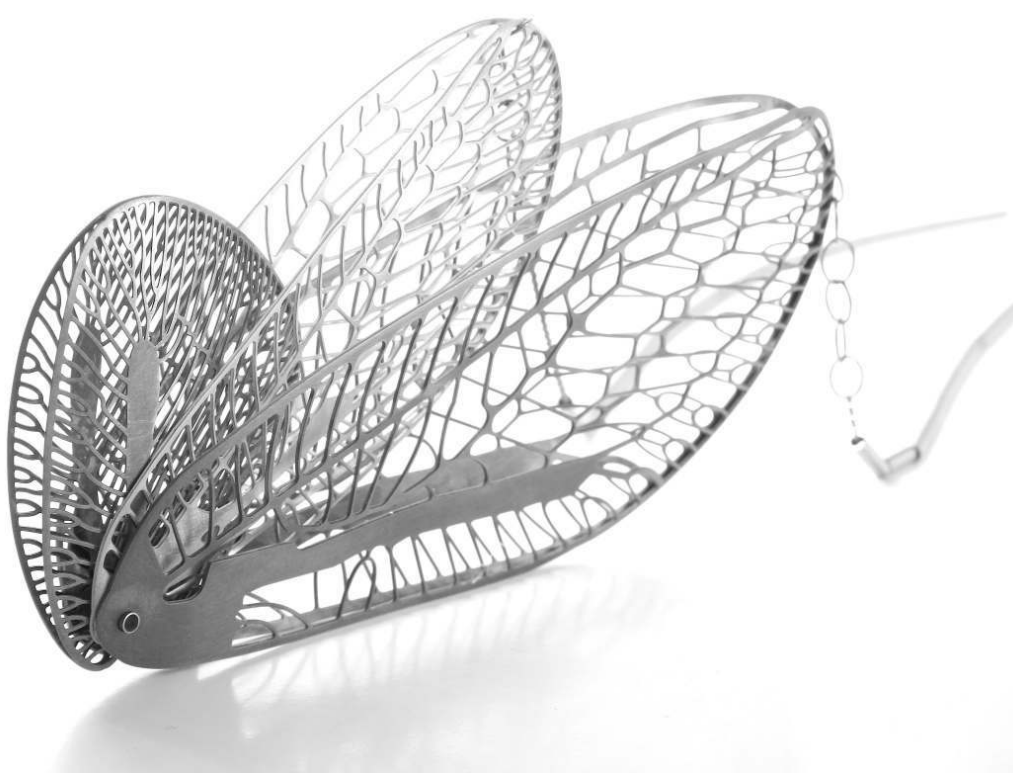

Foto (c) Andrea Vaggione

\section{Ana Carolina Escobar (Colombia)}

47 La nostalgia por su patria y de todo aquello que la ayudo a construirse como persona hace que Ana Carolina Escobar se pregunte sobre las consecuencias de la distancia. Hasta donde las fronteras mentales son mas fuertes que las geográficas y que es lo que la hace sentir , cotidianamente, pasar de un lado al otro de esas fronteras.

Para Ana Carolina el tiempo actúa como un filtro que selecciona ciertos eventos, momentos o recuerdos y hace que esas fronteras mentales se mezclen, redibujándose para crear nuevas formas. Que queda de todos estas "ires y venires" y cómo en ese proceso, la identidad continua a forjarse lejos de nuestras raíces. 


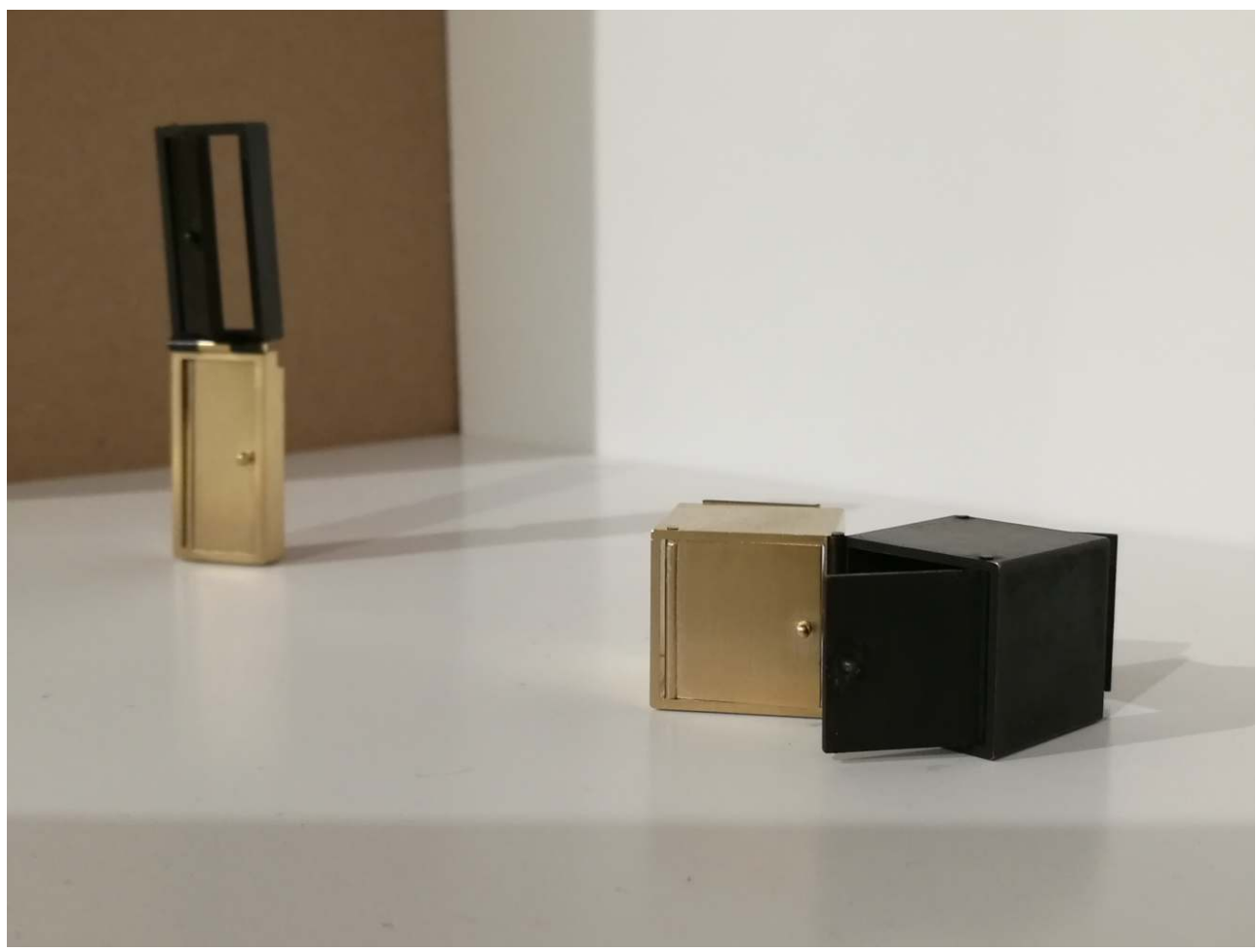

Foto @ Andrea Piñeros

Para ilustrar estas fronteras y esos umbrales donde dialoga el aquí y el allá, Ana Carolina nos propone una serie de piezas compuestas de dos puertas articuladas entre si. La una es en metal dorado y la otra en metal oxidado, para evocar los pasajes de una realidad a otra y los cambios que esto conlleva. Entre otros: la coexistencia de los contrarios, lo intimo y lo universal, la protección y la libertad, la presencia y la ausencia.

\section{Andrea Piñeros (Colombia)}

Explorar y tratar de entender, a partir de un punto de vista personal, las razones que empujan a los seres humanos a ir mas allá de sus propias fronteras, es la forma que Andrea Piñeros aborda la temática de la exposición “ AILLEURS”

Desde muy joven, curiosa de saber como la gente vivía en otros lados, como hablaba, como reía, Andrea siempre soñó con viajar. Al crecer, esa ilusión se volvió una necesidad sintiendo que debía liberarse de los limites que su cultura le imponía. Aventurarse a lo desconocido fue la oportunidad de tener nuevas perspectivas.

Viajar le enseño a Andrea a conocer otras formas de vivir, con otras costumbres y valores. Sus ilusiones fueron confrontadas a esa otra realidad desconocida. Aunque se liberó de todo aquello que su cultura le imponía, al establecerse en otro país, entendió que la adaptación significaba entrar en nuevos esquemas y que de nuevo se encontraba encerrada dentro de otros limites.

No pertenecer a ningún lado puede ser una situación poco confortable. "Ya no soy ni de aquí ni de allá" dicen aquellos que se han ido de su patria. Pero al mismo tiempo es una situación que nos obliga a estar en movimiento, a cuestionarnos sobre lo que realmente 
somos y a despojarnos de lo inútil. Andrea Piñeros considera que finalmente es en esta situación que encuentra la libertad de ser lo que realmente se es.

Broche “Mirages" de Andrea Piñeros

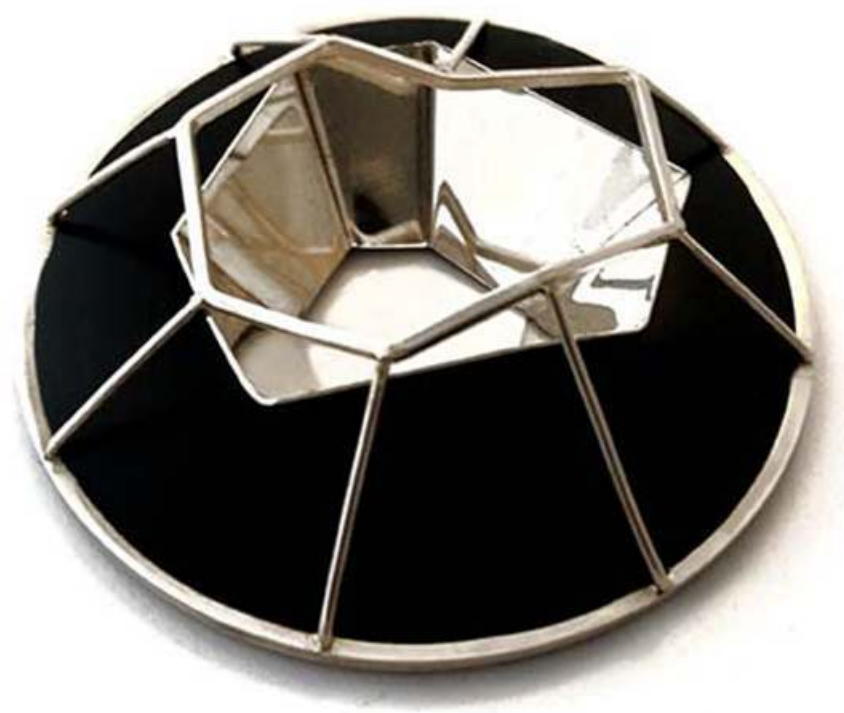

Foto (c) Andrea Piñeros

\begin{abstract}
ideas que Andrea Piñeros desea reflejar con este proyecto, utilizando un registro de formas, colores y acabados en la concepción de sus joyas.
\end{abstract}

Las superficies de métales pulidos que se reflejan entre ellas, simbolizan la ilusión. El pigmento negro, el aburrimiento y las diferentes estructuras, llenas o vacías, las prisiones culturales que los humanos nos imponemos.

Los títulos de sus piezas son parte importante para la comprensión de su intención artística. Andrea aprecia particularmente la reacción del publico frente a la explicación de su obra, pues los ecos son diferentes en función de cada persona.

57

El tema "Ailleurs" tratado a partir de un punto de vista individual, es un tema universal que concierne cada uno de nosotros, en nuestra historia y en nuestros sueños. 


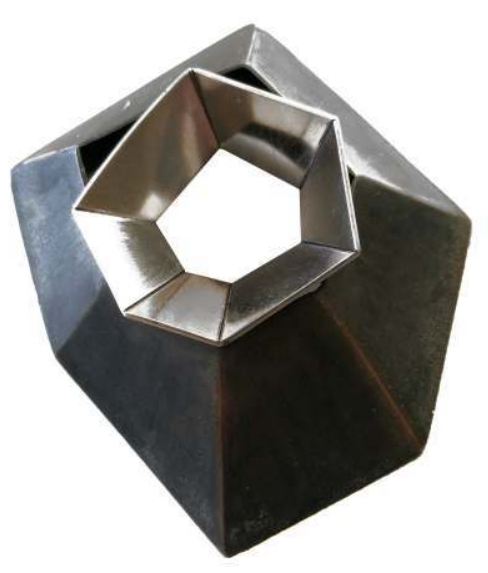

\section{AUTOR}

\section{ANDREA PIÑEROS}

Andrea Piñeros nace en 1972 en Bogota. Vive desde 1997 en París

Andrea se dedica a la joyería después de sus estudios de diseño en Bogota. Instalada en París, integra l'AFEDAP, una escuela especializada en joyería contemporánea donde sale graduada con mención. Rápidamente comienza a trabajar en talleres de fabricación para la alta costura y en paralelo monta un colectivo con el que organiza eventos artísticos. 
En el 2002 es llamada a enseñar en la escuela en la que se especializó primero en técnica y luego en diseño y concepción de joyería, y entre el 2005 y el 2008 es consejera externa del proyecto de desarrollo de joyería con la Universidad Autónoma de Colombia en Bogota.

En el 2010 instala su taller donde fabrica sus colecciones y sus piezas unicas. En el 2013 expone en el museo de artes y diseño en Nueva York y en el 2014 gana la beca de concejería para empresas creativas, de la fundación "Nina Carasso", asignada por el organismo "Ateliers de Paris". En el 2011 se crea la asociación "D’un bijou à l'autre" que ella presida actualmente. Este grupo organiza en París el evento internacional de joyería contemporánea "Parcours bijoux" en 2013, con la participación del Museo de Artes Decorativas de París, y en el 2017 con la participación del Museo de Arte Moderno de París. 